\title{
LA COMPOSICIÓN JURISPRUDENCIAL DEL DEBER DE LEALTAD COMO LÍMITE A LA LIBERTAD DE EXPRESIÓN EN EL CONTEXTO DE LOS PARTIDOS POLÍTICOS
}

\section{The case-law composition of the duty of loyalty as a limit for freedom of speech within political parties}

\author{
DANIEL CAPODIFERRO CUBERO \\ Universidad Nacional de Educación a Distancia \\ dcapodiferro@der.uned.es
}

Cómo citar/Citation

Capodiferro Cubero, D. (2020).

La composición jurisprudencial del deber de lealtad como límite

a la libertad de expresión en el contexto de los partidos políticos. Anuario Iberoamericano de Justicia Constitucional, 24(2), 393-418. doi: https://doi.org/10.18042/cepc/aijc.24.12

\section{Resumen}

La libertad de expresión es un elemento esencial en el sistema democrático, en especial dentro del debate político, donde apenas caben restricciones. Al menos para el común de los ciudadanos, ya que la jurisprudencia constitucional española impone a los afiliados a un partido político una limitación especial basada en el deber de lealtad a la organización, legitimando la imposición de sanciones disciplinarias para los que critiquen públicamente las decisiones de sus órganos directivos. Esta solución supone reforzar la posición de las élites partidistas frente a la del afiliado, especialmente si este es parte de una minoría discrepante, por lo que cabe plantear una interpretación alternativa de dicho deber, considerando las exigencias del principio de democracia interna, que permita a la libertad de expresión cumplir su función al servicio de la opinión pública al tiempo que sirve de contrapeso dentro de los partidos políticos. 


\section{Palabras clave} liado.

Libertad de expresión; partidos políticos; democracia interna; derechos del afi-

\section{Abstract}

Freedom of speech is a core element of democratic system, particularly within political debate, where restrictions are hardly admitted. At least when it is exercised by ordinary citizens, because Spanish constitutional case law imposes on members of political parties a particular limitation based on the duty of loyalty to the organization, which legitimizes the imposition of disciplinary sanctions for those who publicly criticize the decisions of its governing boards. This solution involves a reinforcement of the position of partisan elites against individuals, particularly if these are members of a dissenting minority. Consequently, the need of an alternative interpretation of that duty arises, taking into account the requirements of the principle of internal democracy and allowing individual freedom of expression to fulfil its role at the service of public opinion as well as it works as a counterweight within political parties.

\section{Keywords}

Freedom of speech; political parties; internal democracy;rights of the members of political parties. 


\section{SUMARIO}

I. INTRODUCCIÓN. II. LA FUNCIÓN PRIVILEGIADA DE LA LIBERTAD DE EXPRESIÓN EN EL ESTADO DEMOCRÁTICO. III. EL PARTIDO POLÍTICO COMO CONTEXTO PARTICULAR PARA EL EJERCICIO DE LA LIBERTAD DE EXPRESIÓN: 1. La realidad de la democracia interna de los partidos. 2. En busca de un concepto de «lealtad» como rasgo definitorio del régimen jurídico del afiliado. IV. EL DEBER DE PRESERVAR LA IMAGEN DEL PARTIDO COMO LÍMITE A LA LIBERTAD DE EXPRESIÓN DEL AFILIADO DERIVADO DEL DEBER DE LEALTAD. V. VALORACIONES FINALES. BIBLIOGRAFÍA.

\section{INTRODUCCIÓN}

La especial posición que ocupan los partidos políticos como nexo de unión entre el electorado y el poder es un rasgo definitorio esencial de la democracia constitucional moderna, siendo los responsables de organizar y activar la voluntad política de la masa electoral (Loewenstein, 1976: 94) en un contexto y circunstancias donde las instituciones de democracia directa no permitirían por sí mismas asegurar ni la limitación del poder ni las libertades de los ciudadanos (Aragón Reyes, 2016: 24). Esto permite describir el modelo político con el ya recurrente término "Estado de partidos», que ilustra la particular interacción que se produce en su seno entre el sistema de partidos y el estatal, dotando a este último de funcionalidad y legitimidad democráticas (García-Pelayo, 1986: 86) gracias al papel mediador que estos entes colectivos realizan entre la sociedad y las instituciones, lo que los coloca en una posición de preeminencia funcional, incluso por encima de los órganos constitucionales del poder, que altera el modelo mismo de representación (Torres del Moral, 1982: 14).

Así, dado que su proyección trasciende la dimensión propia del ámbito asociativo privado para repercutir de manera directa en el del aparato estatal, resulta imposible desligar lo que sucede, y cómo sucede, dentro de los partidos y su actuación en la esfera pública. Por ello, a imagen y semejanza del Estado, la exigencia constitucional de ajustar su estructura y funcionamiento al principio democrático resulta inexcusable (Flores Giménez, 1998: 23-24). También en lo relativo a la manera de articular los derechos de sus miembros, ya que los partidos representan el primer espacio del proceso de participación política (Vírgala Foruria, 2015: 228), en el que la libertad de expresión no solo es un derecho fundamental necesitado de protección, sino también un instrumento 
esencial para articular la comunicación libre necesaria en cualquier estructura democrática, particularmente cuando es ejercida por las minorías.

Sin embargo, en estas organizaciones el ejercicio de la libertad de expresión es una cuestión sensible, pues los cuadros tienden a reforzar su posición en ellas mediante fórmulas con las que arrinconan a las corrientes discrepantes eliminando o minimizando los debates internos, reduciendo la eficacia de los mecanismos de control sobre su actividad (Gómez Yáñez, 2016: 54-55). Si ya a principios del siglo xx Michels (1969: 200-201) advertía sobre la tendencia de las élites partidistas a reivindicar la importancia de la obediencia y la subordinación como valores necesarios para la supervivencia del partido como excusa para fiscalizar y censurar, a través de la disciplina interna, la libertad de expresión de todos aquellos que pudieran suponer una amenaza para su posición, esto se ha agravado en la actualidad. Porque las exigencias constitucionales contrastan con la realidad de unos partidos no solo fuertemente oligárquicos en su estructura (Tajadura Tejada, 2015: 79), sino también cuyos procesos decisorios responden cada vez más a un modelo aclamativo que poco tiene que ver con la democracia. En ellos las bases, lejos de participar verdaderamente en la adopción de acuerdos, limitan su papel a secundar las decisiones adoptadas por los órganos directivos, sin espacio real para una discrepancia frente a la que estos no dudarán en utilizar los mecanismos disciplinarios de la organización.

Así, el conflicto entre el ejercicio de la potestad sancionadora que deriva de la facultad de autoorganización reconocida a los partidos y la libertad de expresión de los afiliados presenta no solo una evidente trascendencia constitucional (Salvador Martínez, 2019: 393-394), sino también una considerable complejidad. Porque más allá de su dimensión subjetiva, la exigencia constitucional de democracia interna debería tener en el ecosistema partidista implicaciones diferenciadoras en relación a otros entes asociativos, en especial en cuanto a la garantía de aquellos derechos de los afiliados necesarios para su participación política. Y, por otra parte, ya que se trata de manifestaciones públicas, también hay que considerar en el momento de valorar su admisibilidad que un exceso de permisividad en la crítica hacia los partidos, en principio positiva para la opinión pública, podría derivar en un descrédito excesivo de las instituciones estatales al ser estos quienes las ocupan (Burguera Ameave, 2015: 674-675).

Sin embargo, el Tribunal Constitucional parece enfocar la cuestión como un problema esencialmente privado, enmarcado sin más en el derecho de asociación. En su Sentencia 226/2016, de 22 de diciembre, recurre al deber de lealtad a la organización como único fundamento para privar de protección a las manifestaciones de una afiliada a pesar de reconocer expresamente su 
relevancia e interés público ${ }^{1}$. Simultáneamente, reivindica la plena vigencia de los derechos fundamentales dentro de los partidos, lo que genera en conjunto un discurso no solo incompleto, sino ciertamente contradictorio.

\section{LA FUNCIÓN PRIVILEGIADA DE LA LIBERTAD DE EXPRESIÓN EN EL ESTADO DEMOCRÁTICO}

Desde un punto de vista subjetivo, la amplia jurisprudencia constitucional que ha abordado la libertad de expresión coincide sustancialmente en caracterizarla como el derecho a manifestar los propios pensamientos, ideas $\mathrm{u}$ opiniones, incluyendo tanto creencias como juicios de valor ${ }^{2}$. Al igual que la libertad de información, este derecho tiene una dimensión esencialmente pública, de manera que ambos amparan no solo la emisión del mensaje informativo o valorativo, sino la posibilidad de dotarlo de una difusión amplia para que pueda llegar a un público indeterminado de inicio (Torres del Moral, 2002: 541), protegiendo así no solo el objeto del proceso comunicativo, sino también la propia forma en la que este se produce. En su doble faceta como prerrogativas individuales y garantías de la comunicación pública libre, las libertades comunicativas constituyen conjuntamente un elemento básico para las relaciones sociales dentro de cualquier estructura organizativa humana (Navas Castillo, 2009: 89), con independencia de su tamaño o naturaleza, siempre y cuando su funcionamiento se base en la interacción libre entre sujetos.

Sin embargo, el tipo de mensaje que sea objeto de la comunicación derivará en «matices peculiares que modulan su respectivo tratamiento jurídico» a partir de uno u otro derecho ${ }^{3}$. Así, mientras que la protección de la libertad de información se construye alrededor de la noción de veracidad

1 El FJ 10.a) de la STC 226/2016, de 22 de diciembre, reconoce no solo que «las ideas expresadas por la afiliada versaban, sin lugar a dudas, sobre un tema no solo de interés general y de relevancia pública, sino perteneciente al ámbito sobre el que se proyecta específicamente el mandato constitucional de funcionamiento democrático de los partidos políticos», sino que con ellas se trasladaban «a la opinión pública dos debates de interés general: el relativo a los procedimientos internos de selección de candidatos a las elecciones, y el referido a la libertad de expresión en el seno del partido político». Ante esto, resulta extraña la simplicidad con la que el Tribunal acaba por denegar el amparo a la recurrente.

2 STC 6/1988, de 21 de enero, FJ $5^{\circ}$.

3 STC 165/1987, de 27 de octubre, FJ $10^{\circ}$. 
del mensaje y del interés de su contenido como noticia ${ }^{4}$, dando una cobertura particular a los profesionales del periodismo, el ejercicio de la libertad de expresión en sentido estricto supone actuar sin pretensión de sentar hechos o afirmar datos objetivos ${ }^{5}$. Ante la dificultad práctica para distinguir una de otra, la jurisprudencia ha determinado que la concreción del derecho en juego deberá hacerse atendiendo al elemento predominante en el mensaje o a la intención del emisor al componerlo ${ }^{6}$, como resultado de una valoración cualitativa donde se considerará tanto la literalidad de aquel como su contexto (Moretón Toquero, 2015: 29). Por tanto, mientras que la libertad de información protege todas las actividades necesarias para la preparación y difusión del mensaje noticioso, la libertad de expresión ampara la comunicación sin trabas del propio pensamiento por parte de cualquiera (Solozábal Echavarría, 1991: 81), aunque no por ello de manera incondicionada.

Porque no cualquier juicio de valor manifestado públicamente puede ser considerado un ejemplo de libertad de expresión. Si bien este derecho ampara en principio la realización de cualquier crítica, por áspera, incómoda, molesta u ofensiva que pueda resultar para su destinatario, incluso tratándose del propio Estado o algún sector de la población ${ }^{7}$, no por ello se puede dejar de exigir un cierto grado de coherencia y relación discursiva entre el núcleo del mensaje y los términos concretos empleados para darle forma. Con ello se impone un límite, que podríamos considerar de carácter interno, al derecho basado en la forma de la exposición pública. Así, no solo los insultos o cualquier expresión «formalmente injuriosa» o vejatoria resultan automáticamente excluidas del ámbito de protección del derecho, sino también aquellas innecesarias para la crítica por no guardar relación con las ideas u opiniones que motivan y fundamentan la exposición en cada caso ${ }^{8}$, por mucho que se trate de afirmaciones no susceptibles de prueba. Por su parte, el Tribunal Europeo de Derechos Humanos ha aceptado que la intensidad de la protección dispensada pueda hacerse depender de la existencia de una conexión circunstancial entre el juicio de valor y una base fáctica demostrable (de Miguel Bárcena, 2015: 85); es decir, de que exista cierta correspondencia de la opinión manifestada con

4 Veracidad relativa, como exigencia de la debida diligencia en la comprobación de la información (STC 1/2005, de 17 de enero, FJ 30). El Tribunal Constitucional también ha señalado que el derecho a comunicar y recibir información solo se proyecta sobre aquellos hechos «que pueden considerarse noticiables» (STC 6/1988, de 21 de enero, FJ 5\%).

5 STC 139/2007, de 4 de junio, FJ 6º.

6 STC 29/2009, de 26 de enero, FJ $2^{\circ}$.

7 STEDH, Handyside c. Reino Unido, no 5493/72, 7 de diciembre de 1976, par. 49.

8 STC 226/2016, cit., FJ 5º donde se sintetiza la doctrina constitucional sobre la cuestión. 
hechos ${ }^{9}$, hasta el punto de desaparecer cuando esta no se pueda apreciar en modo alguno ${ }^{10}$.

Pero además de garantía subjetiva, la libertad de expresión se ha calificado como el instrumento esencial para el correcto funcionamiento del sistema democrático. Al asegurar la libre circulación de ideas y juicios de valor que permite a los ciudadanos formar sus opiniones y participar de modo responsable en los asuntos de la colectividad, sirve para dar forma a la opinión pública libre ${ }^{11}$. Por ello disfruta de una «posición preferente» que se traduce en una especial protección cuando entre en conflicto con otros bienes jurídicos o intereses, ya sean los derechos de la personalidad expresamente referidos en el art. 20.4 CE o aquellos propios de situaciones concretas amparados en razones de índole laboral, profesional o, incluso, política que han sido admitidos doctrinal y jurisprudencialmente como posibles límites (Torres del Moral, 2002: 544).

En estos términos, el propio Tribunal de Estrasburgo ha determinado que solo serán legítimas aquellas medidas nacionales restrictivas de la libertad de expresión que, además de estar previstas por ley y justificadas por alguno de los fines previstos en el art. 10.2 $\mathrm{CEDH}$, resulten necesarias dentro de una sociedad democrática, lo que supone que deben estar basadas en algo más que razones de oportunidad o pertinencia y ser proporcionales, un criterio con el que el Tribunal se ha mostrado bastante estricto (Serrano Maíllo, 2011: 583-584). Pero no hasta el punto de entender que este derecho goza de una prevalencia incondicional, pues tal cosa supondría plantear una inexistente superioridad jerárquica de la libertad de expresión en relación al resto de derechos (García Canales, 2002: 494). Esta idea significa que las excepciones que se planteen frente a ella deben ser interpretadas de manera restrictiva ${ }^{12}$, estableciendo una presunción inicial a su favor que, eso sí, operará únicamente cuando se compruebe que su ejercicio resulta útil para el interés general y la formación de la opinión pública. En tal caso, la legitimidad de cualquier limitación a la libertad de expresión se hace depender de la concurrencia de una «necesidad social apremiante» que pueda desplazar al interés general como principal valor a proteger ${ }^{13}$.

9 STEDH, E.S. c. Austria, no 38450/12, de 25 de octubre de 2018, par. 48.

10 STEDH, Atamanchuk c. Rusia, no 4493/11, de 11 de febrero de 2020, par. 61.

11 STC 6/2020, de 27 de enero, FJ 3o, por citar una de las más recientes dentro de la innumerable lista de resoluciones que se expresan en este sentido.

12 STC 226/2016, cit., FJ $5^{\circ}$ en relación a la doctrina del Tribunal Europeo de Derechos Humanos.

13 Véase SSTEDH, Stoll c. Suiza, no 69698/01, 10 de diciembre de 2007, par. 101; o, especialmente, Bédat c. Suiza, no 56925/08, 29 de marzo de 2016, par. 48. 
Adicionalmente, los Estados también están obligados a adoptar medidas que aseguren la eficacia de este derecho en las relaciones entre particulares ${ }^{14}$, equilibrando el interés general con los individuales concurrentes ${ }^{15}$, por lo que no parece que puedan inhibirse sin más en relación a las vicisitudes que acontecen en ámbitos que de algún modo puedan considerarse privados. Esto tiene una proyección obvia en las relaciones contractuales, pero quizá más importante aún en los partidos políticos, al ser los protagonistas institucionales del sistema democrático y constituir el espacio donde se empieza a construir esa opinión pública a cuyo servicio se coloca la libertad de expresión como garantía de la existencia de opciones plurales.

La jurisprudencia ha articulado el concepto de opinión pública esencialmente alrededor de cuestiones políticas (de Miguel Bárcena, 2015: 99), por lo que aquellas manifestaciones que respondan a la consideración de «discurso político» son las que deberán resultar más protegidas frente a posibles limitaciones $^{16}$. Así, se ha establecido que quienes se dedican a actividades políticas están más expuestos a la crítica que los ciudadanos anónimos, asumiendo que consienten de algún modo soportar una mayor intromisión en sus derechos personalísimos (García Canales, 2002: 499). Esto se puede predicar de cualquier foro donde esta composición de la opinión pública se produzca y deba ser asegurada, en la medida en que su formación es un proceso progresivo donde todas las fases influyen en la calidad democrática general. Por esta razón, la doctrina de la posición preferente también debería resultar aplicable a las manifestaciones realizadas por afiliados de un partido sobre sus decisiones organizativas, con el consiguiente efecto sobre la esfera personal de los responsables de las mismas cuando se trata de críticas de cierta entidad (Salvador Martínez, 2019: 405). Eso sí, siempre que objetivamente contribuyan al proceso de formación de la voluntad política al que parece asimilarse la opinión pública. La cuestión es, entonces, cómo se conciba ese proceso.

En este sentido, Habermas (2005) apunta que, en relación a la toma de decisiones en el Estado, la opinión pública puede construirse bien mediante un mecanismo de simple asentimiento de los ciudadanos en relación a discursos predefinidos por quienes están o quieren lograr una posición de poder, bien mediante procesos públicos deliberativos de naturaleza dialógica donde, partiendo de un consenso de fondo, se busca el acuerdo sobre la ordenación de las relaciones sociales. Bajo la primera concepción, la opinión pública como

14 STEDH, Appleby y otros c. Reino Unido, no 44306/98, 6 de mayo de 2003, par. 39; más recientemente, Kaboğlu y Oran c. Turquía, no 1759/08, 50766/10 y 50782/10, 30 de octubre de 2018, par. 71.

15 STEDH, Palomo Sánchez y otros c. España, no 28955/06, 28957/06, 28959/06 y 28964/06, 12 de septiembre de 2011, par. 54.

16 STEDH, Bédat c. Suiza, cit., par. 49. 
interés constitucional sería un simple agregado de pareceres o puntos de vista cerrados y completos sobre cuestiones de interés general que están a disposición de los ciudadanos en el mercado de las ideas para que estos expresen libremente a cuáles se adhieren. Así se concibe el pluralismo de un modo rígido, donde cabrían pocas restricciones sobre las manifestaciones externas pero sí serían necesarias limitaciones más fuertes dentro de los entes colectivos que generan los discursos para que estos puedan ser proyectados de modo homogéneo.

Sin embargo, si se entiende el pluralismo, siguiendo al Tribunal Constitucional alemán, como la plasmación en el espacio público de argumentaciones y contraargumentaciones en relación a ideas presentadas libremente (Vidal, 2014: 254 ${ }^{17}$, la opinión pública libre solo resulta garantizada si las ideas o juicios de valor contribuyen a la participación política responsable mediante el diálogo, el debate y la construcción de discursos razonados que hagan evolucionar los distintos planteamientos. Se añade así un componente dinámico al pluralismo que hace depender la legitimación democrática del sistema de la presencia de unas determinadas condiciones en la comunicación más allá de requisitos formales, lo que implicaría en última instancia una diversa manera de valorar la admisibilidad de las modulaciones que puedan plantearse a la libertad de expresión. Así, sin perjuicio del límite general al proceso democrático que supone la necesaria garantía de los derechos fundamentales, todo ejercicio de esta libertad que presente un componente proactivo debería ser menos susceptible de ser modulado en cualquier ámbito. Y, en particular, en aquellos entornos donde se exige respeto por el principio democrático, como son los partidos políticos a pesar de su naturaleza privada.

\section{EL PARTIDO POLÍTICO COMO CONTEXTO PARTICULAR PARA EL EJERCICIO DE LA LIBERTAD DE EXPRESIÓN}

\section{LA REALIDAD DE LA DEMOCRACIA INTERNA DE LOS PARTIDOS}

Desde un momento muy temprano el Tribunal Constitucional estableció que los partidos políticos no dejan de ser en última instancia formas particulares de asociación. Y como entes privados fundamentan su existencia en el art. $22 \mathrm{CE}$, que «se proyecta sobre la totalidad del fenómeno asociativo en sus muchas manifestaciones este derecho y modalidades» ${ }^{18}$. No obstante, se trata de «organizaciones sociales con relevancia constitucional» que ejercen una función pública muy concreta ${ }^{19}$ : la de ser el principal instrumento para

17 Véase BverfGE 12, 113, caso Schmid c. Revista Spiegel, 25 de enero de 1961.

18 SSTC 3/1981, de 2 de febrero, FJ $1^{\circ}$, y 5/1996, de 16 de enero, FJ $6^{\circ}$.

19 STC 76/2019, de 22 de mayo, FJ 50. 
la participación política del ciudadano y la primera forma de expresión del pluralismo y de la formación y manifestación de la voluntad popular en el Estado democrático ${ }^{20}$, que responde esencialmente a un modelo representativo $^{21}$.

Por esta razón no se puede dudar del carácter prescriptivo y vinculante de la exigencia de adecuar su estructura y funcionamiento interno a reglas democráticas que se contiene en el art. 6 CE (Pérez-Moneo, 2012: 106), una restricción especial por el tipo de asociación cuya finalidad es tutelar ciertos bienes o derechos distintos a aquellos de los que es titular el partido como persona jurídica (Gómez Montoro, 2002: 94). Y si bien este principio se impone igualmente a otras organizaciones estables que actúan de algún modo en la vida política representando intereses concretos y por ello deben participar del principio democrático general que define el Estado (Gallardo Moya, 1996: 240), caso de los sindicatos y asociaciones empresariales, colegios profesionales y organizaciones profesionales, los partidos políticos presentan rasgos específicos que hacen pensar que, para ellos, su contenido debe ser claramente diferencial. En primer lugar, porque su vínculo lo es con el conjunto de la población y los intereses generales, y no con colectivos concretos. Pero sobre todo como consecuencia de sus funciones, orientadas en última instancia a conectar la sociedad con las instituciones políticas gracias a su posición como entes híbridos entre ambas esferas (Gómez Yánez, 2016: 46), lo que sugiere la conveniencia de cierta equiparación entre ellas en cuanto a sus reglas esenciales con el fin de que esa composición se canalice de un modo verdaderamente libre (Fernández Segado, 2004: 112). La propia jurisprudencia constitucional reconoce que "difícilmente pueden los partidos ser cauces de manifestación de la voluntad popular e instrumentos de una participación en la gestión y control del Estado que no se agota en los procesos electorales, si sus estructuras y su funcionamiento son autocráticos» ${ }^{22}$.

En consecuencia, parece razonable pensar que el sentido de la democracia interna en el caso de los partidos deberá aproximarse en todo lo posible al que se predica del conjunto del sistema, tal y como es concebido actualmente. Esto es, como sinónimo de pluralismo político y organizativo (García Pelayo, 1977: 51). Eso sí, dentro del acuerdo ideológico en el que teóricamente se basa la vinculación a un partido como expresión de una «voluntad política coincidente» que agrupa a los individuos alrededor del mismo (Kelsen, 1934: 37). Esto supone que si bien su facultad de autoorganización no puede resultar suprimida, sí se verá limitada de un modo importante (Flores Giménez, 1998: 66), ya que, en todo caso, en el interior de los partidos deberían asegurarse

20 STC 48/2003, de 12 de marzo, FJ 6․

21 STC 31/2015, de 25 de febrero, FJ $3^{\circ}$.

22 STC 56/1995, de 6 de marzo, FJ 3º. 
ciertos extremos: la participación libre de todos los miembros del colectivo en la toma de decisiones, la existencia de garantías de que las decisiones responden a la voluntad mayoritaria o al consenso mediante mecanismos de control de las élites y, no menos importante, el respeto por las minorías y sus libertades políticas. Algo solo posible reconociendo la conexión necesaria entre el principio de democracia interna y la plena garantía de los derechos constitucionales de los afiliados (Vírgala Foruria, 2015: 229).

Sin embargo, la Ley Orgánica 6/2002 de Partidos Políticos (LOPP) ha confiado en exclusiva a la autorregulación el respeto a la democracia interna. Asumiendo de un modo excesivamente optimista que los aparatos y los líderes partidistas se autolimitarán y aceptarán voluntariamente la existencia de frenos y contrapesos (Garrido López, 2017: 329), su redacción original presentaba considerables carencias en cuanto al control democrático de los dirigentes partidistas (Tajadura Tejada, 2015: 89-90), que no se solucionaron con la reforma operada por la LO 3/2015. Al contrario, el actual art. 6 LOPP ha reforzado formalmente la autonomía organizativa del partido afirmándola al mismo nivel que la exigencia de democracia interna, de modo que esta parece concebirse como una injerencia externa que, a la vista del parecer expresado en la STC 226/2016, debe ser limitada para asegurar un espacio de autocomposición para el partido (FJ $6^{\circ}$ ). En el mismo apartado del fallo parece darse por bueno que en el art. 7 LOPP el principio de democracia interna no tenga más plasmación que un deber de prever «fórmulas de participación directa de los afiliados [...] especialmente en los procesos de elección de órgano superior de gobierno del partido", cuya concreción queda completamente en manos de la normativa interna de la organización ${ }^{23}$.

En lo que respecta a los derechos de los miembros de un partido, si bien el Tribunal Constitucional ha reconocido su importancia exigiendo su incorporación a los Estatutos, lo cierto es que atribuye simultáneamente un margen de configuración excesivamente amplio al legislador a este respecto, poniendo en duda la verdadera garantía de derechos importantes para la participación política (Salvador Martínez, 2019: 402-403). Todo como consecuencia de integrar estos últimos en el derecho de asociación, cuando no son estrictamente una consecuencia de este, en lugar de ligarlos a la exigencia de democracia interna como sería más lógico (Gallardo Moya, 1996: 247). Se trata de una interpretación forzada que se planteó en la Sentencia 56/1995 y que la 226/2016 hereda sin ambages a pesar de proclamar, luego sin ningún efecto práctico, que el ejercicio de los derechos fundamentales por parte de los afiliados a un partido «adquiere una significación constitucional añadida» por las funciones de esta clase de asociaciones que implica igualmente que la exigencia de reconocimiento en la normativa interna «no transforma los

23 Hasta el punto de que parece dar a entender que tan pobre aspiración constituye una adecuada «respuesta a las exigencias sociales» que piden mayor democracia interna. 
derechos fundamentales de los afiliados en meros derechos de configuración estatutaria», por ser irrenunciables (FJ $6^{\circ}$ ).

$\mathrm{Si}$ a esto se suma que la LOPP no menciona el pluralismo como un principio organizativo o funcional interno de los partidos políticos aun a pesar de constituir un requisito inherente al propio principio democrático y cuando, paradójicamente, el régimen general sí lo contempla en el art. 2.5 de la LO 1/2002, del Derecho de Asociación (LODA) como una premisa vinculante para todo ente asociativo, el resultado es un concepto tremendamente limitado de democracia interna. No solo reducido a una proclama formal, sino desligado del concepto de opinión pública libre. Esto repercute negativamente en las posibilidades de proteger jurídicamente la libertad de expresión de sus miembros, cuya alcance acaba por ser modulable a partir de la cláusula genérica del art. 20.4 $\mathrm{CE}^{24}$. O lo que es lo mismo, por la disciplina interna, lo que lleva a reforzar la naturaleza privada asociativa de los partidos políticos, incluso en contra de sus propios miembros.

\section{EN BUSCA DE UN CONCEPTO DE «LEALTAD» COMO RASGO DEFINITORIO DEL RÉGIMEN JURÍDICO DEL AFILIADO}

La LOPP emplea el término «afiliado» para designar genéricamente a cualquier sujeto ligado libre y voluntariamente a un partido que puede participar de algún modo en sus procesos internos $y$, con ese fin, se somete a la normativa propia del mismo, permitiendo que sea cada partido, en ejercicio de su autonomía organizativa, el que determine en sus Estatutos si existen o no modalidades distintas de membresía que se traduzcan en un régimen de derechos diferenciado ${ }^{25}$. Pero no así en cuanto a las obligaciones, cuyo núcleo básico la Ley considera de aplicación indistinta a cualquier afiliado a excepción de las de naturaleza económica.

Así, el art. 8.5 LOPP, en coincidencia con el régimen general del art. 22 LODA, establece que la unión a un partido político conlleva en todo caso el acatamiento de tres deberes generales: de colaboración con la consecución de las finalidades de la organización, de respeto por lo dispuesto en los estatutos y las leyes, y de cumplimiento de los acuerdos válidamente adoptados por los órganos directivos. El desarrollo de esta previsión corresponde a la normativa de cada partido político, cosa que por lo general se realiza con un marcado

24 STC 226, 2016, cit., FJ 7o.

25 Al igual que la LOPP, los estatutos de los partidos políticos no contienen una definición del término "afiliado». Lo que sí hacen es establecer distintas categorías de participación en función de la voluntad y, normalmente, la contribución económica del sujeto, diferenciando entre «militantes» $\mathrm{y}$ «simpatizantes». 
nivel de ambigüedad que otorga un margen de apreciación considerable a los órganos disciplinarios.

Paralelamente, el Tribunal Constitucional entiende que el ingreso en un partido tiene como consecuencia automática para el sujeto la necesidad de adecuar su comportamiento para dar cumplimiento a lo que denomina de forma indistinta "mínima exigencia de lealtad», «exigencia de colaboración leal» o, simplemente, «deber de lealtad», que se desglosa a su vez en dos dimensiones aparentemente diferenciadas ${ }^{26}$. Por un lado, existiría una obligación de "colaboración positiva» para favorecer el adecuado funcionamiento de la organización que, si bien no se define, parece hacer referencia a un imperativo de actuación en beneficio de ella. Y por otro, un deber de «preservar la imagen pública» del partido de contenido esencialmente negativo, como abstención de realizar cualquier manifestación que le resulte perjudicial. Poniendo esto en relación con la dicción de la ley, que no admite modulación en la aplicación de los deberes derivada del grado de vinculación del sujeto al partido, se puede entender que ambas exigencias afectan por igual a cualquier afiliado ${ }^{27}$, erigiéndose como el principal factor que condiciona su esfera jurídica.

La integración en una asociación requiere como regla general aceptar la sumisión a unos estatutos y, con ello, a los componentes jurídicos y morales que la definen sobre la base de la confianza mutua (Pérez-Moneo, 2012: 64-65). Por ello, la propia organización puede legítimamente negar la incorporación a quienes de modo abierto e inequívoco hayan demostrado no compartir sus planteamientos como forma de mantener la integridad de sus principios definitorios y la eficacia de su actuación (Oliver y Calafell, 2007: 18), mientras no se vulneren el principio de igualdad y la dignidad (Tajadura Tejada, 2015: 90), algo particularmente importante en el caso de las organizaciones que deben expresar el pluralismo ideológico de la sociedad y, por tanto, requieren diferenciarse las unas de las otras en sus planteamientos. Pero no por ello se puede reducir la posición del afiliado a un haz de obligaciones que, bajo ese genérico deber de lealtad, le priven de cualquier capacidad para oponerse o expresar su disconformidad con la actuación del partido. De entenderlo así, sus derechos de participación política pueden resultar fácilmente condicionados por factores que no responden estrictamente a la autonomía de su voluntad ni a la función de la organización.

Porque en el ámbito político el ejercicio del derecho individual de asociación no se basa (o no debería basarse) en la sumisión acrítica a unos determinados dirigentes o estructuras de poder partidista. Se fundamenta en

26 STC 226/2016, cit., FJ 7o.

27 Desarrollando esto, los estatutos de los principales partidos políticos españoles coinciden, salvo matices, en imponer a todo afiliado el deber de respetar la imagen de la organización o de sus miembros. 
la presunción de una afinidad ideológica entre los planteamientos del sujeto y aquellos que la organización presenta o asume como propios que le llevan a unirse a ella para poder ejercer sus derechos de participación política en la esfera pública. Esto hace que la actuación del individuo, además de voluntaria, se pueda considerar coherente, sin perjuicio de que puedan existir otras motivaciones no fiscalizables en la decisión de unirse a un partido concreto. El elemento sobre el que se proyecta la autonomía de la voluntad individual es el sustrato ideológico común, que solo cuando es definido mediante un sistema participativo y libre podrá delimitar el alcance del pluralismo de quienes decidan integrarse o seguir siendo parte de la organización. Por esta razón las limitaciones a los derechos de los afiliados derivadas de decisiones de órganos del partido que no han sido objeto de debate son por definición bastante problemáticas (Flores Giménez, 1998: 209).

Porque si bien la dimensión colectiva del derecho de asociación se asegura a través de la aceptación de los deberes y el correlativo régimen disciplinario que permite garantizar el cumplimiento de las normas internas del partido (Pérez-Moneo, 2012: 78), no se debe olvidar que un partido es en buena medida un medio casi necesario para poder ejercer los derechos individuales de participación política (Gómez Montoro, 2002: 97). Por esa razón sus facultades disciplinarias son instrumentos no solo al servicio del ente colectivo como persona jurídica; también responden a las necesidades de los individuos que la integran con el objetivo de asegurar que estos puedan participar en la conformación y funcionamiento de los órganos asociativos (Solozábal Echavarría, 2001: 100), además de optar al desarrollo de su derecho a los cargos públicos. En el caso de los partidos, mediante mecanismos democráticos que permitan dar forma en cada momento a su discurso y su voluntad materializada en su acción pública. Ciertamente, este carácter evolutivo de los planteamientos partidistas, necesario en términos de subsistencia, implica la posibilidad de desacuerdos sobrevenidos con las opciones mayoritarias, que siempre se pueden solucionar con la salida voluntaria de la asociación. O incluso con la expulsión, pero solo en casos en los que la conducta del afiliado ponga en peligro la existencia o funcionamiento del partido como consecuencia de un ataque a sus principios fundamentales (Hernández Valle, 2002: 479).

Esto debe tenerse en cuenta al definir esos «intereses sociales» respecto de los que se articula el deber de lealtad al partido y cuya protección resulta justificada mediante las sanciones más graves ${ }^{28}$, planteándolos en relación

28 En la STC 218/88, de 22 de noviembre, FJ 1º se aceptó que aquellas conductas lesivas a los «intereses sociales» definidos por la propia organización pueden motivar la expulsión de un socio en la medida en que «la asociación crea no solo un vínculo jurídico entre los socios, sino también una solidaridad moral basada en la confianza recíproca y en la adhesión a los fines asociativos» que deben mantenerse. 
al sustrato común representado por la expresión de la libertad ideológica mayoritaria de sus integrantes que la minoría acata voluntariamente. Esto sin perjuicio de que pueda existir discrepancia manifiesta y esta deba ser respetada y encontrar cauces adecuados de expresión, pues tal cosa es una exigencia del principio democrático. La cuestión que la LOPP no resuelve es cuándo esta disensión, en forma de crítica, deja de ser tolerable para el partido y, consecuentemente, resulta merecedora de sanción grave bajo la forma de expulsión.

En principio, el deber de adecuar el funcionamiento interno a reglas democráticas, también desde un punto de vista material, exigiría limitar esta solución a la concurrencia de causas muy graves previstas en la normativa interna apreciadas en un proceso con todas las garantías. Además, este debería ser siempre revisable judicialmente (Oliver y Calafell, 2007: 19), pues se trata de una medida que tiene una repercusión negativa directa en el derecho de participación política del sujeto, que se ve privado de la vía más cualificada para su ejercicio (Navarro Méndez, 2000: 274). Además, si la sanción es consecuencia del ejercicio de la libertad de expresión constituye una limitación en sede privada de un derecho fundamental particularmente protegido en el ámbito de lo político y esencial para calificar una organización como democrática, lo cual sugiere ser particularmente cautelosos.

Por todo ello, la idea de lealtad como límite a la manifestación de ciertos pareceres debería ser concebida como un mínimo y no como una sumisión total a las directrices de los órganos directivos de la organización, que es precisamente a lo que conduce la falta de garantías de la LOPP. Como reverso de esto, la noción de actuación desleal grave hacia el partido debería también ser interpretada de un modo muy estricto. Nunca asimilada a un pretendido interés privado del partido desligado de los requisitos que imponen las funciones públicas atribuidas y el principio de democracia interna; $y$, desde luego, mucho menos como interés particular de los dirigentes de una estructura de tendencia naturalmente oligárquica. Al hacerlo así se genera una esfera de inmunidad ante la crítica que no se relaciona con la protección y promoción de los derechos del conjunto de individuos que integran la organización y, por tanto, tiene poco sentido, transformando el deber de lealtad en un simple mecanismo de control de la disidencia y refuerzo de la posición de las élites partidistas de cada momento.

Por el contrario, partiendo de la idea de que el deber de lealtad al partido voluntariamente asumido resulta justificado en la medida en que este responde al principio democrático en su actuación interna, las sanciones más graves deberían asociarse a un quebranto importante de dicho principio. Si bien es cierto que la propia organización deberá definir en cada momento a través de sus procesos internos los elementos vertebradores de cohesión que conforman el patrimonio compartido por sus miembros, estos solo se podrán identificar con las decisiones de los órganos directivos, programáticas o de gestión, si estas se corresponden con la confluencia de los intereses de los afiliados y respetan los derechos y las posiciones de las minorías. En ese caso será legítimo 
limitar en su beneficio la libertad de acción individual, considerando toda conducta que se oponga a ellas como desleal y, en consecuencia, merecedora de una respuesta proporcionada. Del mismo modo, también deberían perseguirse en el seno de los partidos aquellas conductas que impidan o dificulten injustificadamente los derechos de participación política de otros afiliados.

No obstante, la viabilidad de tal planteamiento requeriría aumentar la posibilidad de control del poder público sobre las decisiones sancionadoras de los partidos políticos reinterpretando las capacidades de los órganos judiciales al respecto. Es algo que se antoja necesario si se tiene en cuenta que los excesos en esta potestad afectan en última instancia a la calidad democrática del Estado (Salvador Martínez, 2019: 417) y que resulta muy complicado asegurar la imparcialidad de los órganos disciplinarios de los partidos (Vírgala Foruria, 2015: 269). El Tribunal Constitucional parece aceptar esto último en la Sentencia 226/2016 cuando, superando la idea de un control limitado al cumplimiento de los requisitos formales en la imposición de la sanción ${ }^{29}$, apunta su extensión "al análisis material de las causas de expulsión, en particular cuando esas causas pueden entenderse como límites al ejercicio de un derecho fundamental del afiliado en el seno del partido político» (FJ $8^{\circ}$ ). Esta declaración, sin embargo, contrasta con la concepción tan amplia del deber de lealtad que se defiende simultáneamente en el fallo, reduciendo las posibilidades de actuación del afiliado a la aceptación acrítica de cualquier actuación de los órganos partidistas con el fin de proteger la imagen pública de la institución, erigida en centro de toda la argumentación.

\section{EL DEBER DE PRESERVAR LA IMAGEN DEL PARTIDO COMO LÍMITE A LA LIBERTAD DE EXPRESIÓN DEL AFILIADO DERIVADO DEL DEBER DE LEALTAD}

La citada sentencia deduce directamente del deber de lealtad del afiliado una obligación de abstenerse de realizar manifestaciones que induzcan a la sociedad a tener una percepción negativa de su partido, en particular aquellas que puedan llevar «a la opinión pública a considerar que la propia organización no respeta el mandato constitucional de responder a una organización y funcionamiento democrático» ${ }^{30}$. Aunque esto no se presenta como una negación total de la libertad de expresión del sujeto fuera del entorno partidista,

\footnotetext{
29 Antes, la STC 56/1995, cit., FJ 4º, limitó las posibilidades del control jurisdiccional a la verificación de la tipificación de la sanción y la observancia del procedimiento, debiendo este ceñirse a comprobar si la misma era razonable «a la luz de las disposiciones legales y estatutarias aplicables».

30 STC 226/2010, cit., FJ $10^{\circ}$.
} 
cosa que difícilmente encajaría con el principio democrático (Flores Giménez, 1998: 209), sí se trata de un límite específico que, como primera característica y haciendo una interpretación literal de la doctrina constitucional, solo debería operar cuando aquella se ejerza en medios o foros públicos. En los internos no hay razón legítima para imponer a las libertades comunicativas de los afiliados otros límites distintos o más intensos de los que rigen con carácter general, esencialmente los derivados del art. $18 \mathrm{CE}$.

La imagen que el partido proyecta externamente es el resultado de unos procesos de debate y decisión internos que deberían conformarse libremente sin más condicionante que el juego de mayorías. Y para ello, el carácter vinculante y diferenciador de la exigencia de democracia interna del art. $6 \mathrm{CE}$, a imagen y semejanza de lo que sucede en la sociedad, requiere garantizar el libre intercambio de ideas y planteamientos que, sobre el presupuesto de cierto grado de confluencia ideológica de sus miembros, facilite un debate en el seno del partido que le permita no solo evolucionar y adaptarse, sino también valorar sus aciertos y errores pensando en el interés general al que sirve desde su posición constitucional. Cualquier solución en un sentido distinto llevaría a falsear este principio. Sin embargo, el Tribunal Constitucional deja abierta esta posibilidad al afirmar que el reconocimiento de una potestad disciplinaria al partido puede derivar en una restricción de la libertad de expresión «en cuanto a la expresión interna o pública de opiniones y juicios de valor que pueden reputarse perjudiciales para los intereses del partido ${ }^{31}$, asimilando ambos ámbitos sin mayores razones.

Pero aun restringiendo su aplicabilidad solo a las críticas que un afiliado pueda realizar públicamente hacia su partido, se trata de un límite problemático. En buena medida por su carácter impreciso, que impide concretar los términos de la ponderación y no permite apreciar con claridad por qué no se aplica en este caso la doctrina de la posición preferente. Pero también porque parece plantearse como una restricción incondicional y abstracta de la libertad de expresión que operará sin tener en cuenta la realidad de funcionamiento de la organización, algo que no debería obviarse si se pretende que el sistema democrático funcione en los términos debidos.

La referencia al perjuicio grave sobre «la facultad de autoorganización del partido, su imagen asociativa o los fines que le son propios» dificulta la tarea de determinar dónde está realmente la línea que hace que la crítica a las «decisiones de los órganos de dirección del partido que se consideren desacertadas» pierda la cobertura dispensada por la libertad de expresión ${ }^{32}$. Se podría entender que con esto se busca evitar manifestaciones con ánimo lesivo que produzcan un daño malicioso a los principios esenciales del partido (Garrido

31 Ibidem, FJ 70. 
López, 2017: 341), pero entonces el problema se traslada a la definición de esos principios. Y en el momento en el que se asume que esta corresponde a los órganos de dirección de la organización, pero se renuncia a analizar si su actuación realmente responde formal y materialmente a las exigencias de un proceso democrático, cuyo cumplimiento parece darse por supuesto por el mero hecho de haber seguido las formalidades previstas en la normativa estatutaria, se corre el riesgo de reducir los principios comunes del partido, y por tanto el objeto de la lealtad debida del afiliado, a la simple voluntad de los cuadros.

Tampoco ayuda que el Tribunal Constitucional recurra de manera caótica para definir el alcance de la libertad de expresión del afiliado a una miríada de bienes y principios variados y muy complicados de precisar, cuyo único punto común es estar vinculados, aunque sea de un modo vago e impreciso, al carácter asociativo del partido (Salvador Martínez, 2019: 411). No obstante, la realidad es que en la práctica todos ellos confluyen en uno solo ${ }^{33}$, que bien podría denominarse «imagen institucional» del partido ante la sociedad: una suerte de reputación pública que le permite generar una percepción social de unidad de discurso y acción a partir de la que plantear su actuación externa en un entorno electoral competitivo. Aunque eso suponga negar la expresión pública del pluralismo interno, o no permitir distinguir la voluntad generada por un proceso asociativo realmente democrático de aquellos intereses puramente individuales de quienes, con mayor o menor respaldo, ocupen ciertos puestos de poder.

Esta imagen institucional se presenta como un valor implícito a la posición y las funciones de los partidos, traduciéndose en una especial inmunidad frente a la crítica desde dentro que pueda afectar a su buena reputación, concebida aparentemente como una presunción inatacable. Ciertamente, la consideración pública de la que disfruten estas organizaciones, bajo la forma de credibilidad, es un factor íntimamente relacionado con sus objetivos y funciones (Burguera Ameave, 2015: 672), ya que estas se realizan presentándose ante el electorado y confiando en ser percibido como idóneo y digno de confianza suficiente como para asumir el ejercicio del poder o la función de

33 Lo cierto es que la sentencia emplea un término distinto prácticamente en cada una de las ocasiones en que se refiere al bien jurídico en el que se concreta el deber de lealtad que limita la libertad de expresión, recurriendo a los «intereses del propio partido», su «imagen pública», los "fines sociales» o "los fines que le son propios», la necesidad de «favorecer su adecuado funcionamiento», el deber de "colaboración leal», o, incluso, los «lazos de cohesión interna» de la organización, todos ellos presentados como valores que el partido está legitimado para proteger como consecuencia de su «extensa facultad de autoorganización», que parece más dirigida a construir una imagen electoral fuerte que a resolver los problemas internos o perseguir posibles conductas antidemocráticas. 
contrapeso al mismo. No obstante, bien entendido, este valor puede encontrar mejor acomodo en el art. $18 \mathrm{CE}$ antes que en el 22, teniendo en cuenta que los partidos políticos, como producto del ejercicio de derechos fundamentales, son titulares del derecho al honor al igual que cualquier persona jurídica (Gómez Montoro, 2002: 105).

El Tribunal Constitucional ya había reconocido esto unos años antes en su Sentencia 79/2014, de 28 de mayo. Allí determinó que no cabía «excluir a los partidos políticos de la protección que dimana del derecho al honor frente a aquellas afirmaciones y expresiones que los difamen o los hagan desmerecer en la consideración ajena», si bien sugirió que su función como «instrumento esencial para la participación política y, consecuentemente, para la formación y existencia de una opinión pública libre» les obliga a soportar un mayor grado de crítica ${ }^{34}$. En este sentido, el Tribunal de Estrasburgo ha señalado que los límites de la libertad de expresión se amplían cuando el destinatario de la crítica es cualquier sujeto que participa de manera relevante en el proceso político, sea un partido o un individuo indistintamente, en la medida en que de forma inevitable y consciente se expone a un escrutinio más estricto de todas sus palabras y actos por parte tanto de los periodistas como del público en general ${ }^{35}$, si bien también se exige que tales afirmaciones se encuadren en un discurso o debate político o versen sobre asuntos de interés general ${ }^{36}$. En tales circunstancias parece que habría poco espacio para entender que una restricción a la libertad de expresión es necesaria en el contexto de una sociedad democrática, sobre todo si a través de la crítica se evidencia un mal funcionamiento del partido político o una decisión arbitraria de sus órganos que afectan a su idoneidad funcional. Incluso se podría pensar que revelar tales cosas generaría un efecto beneficioso para el conjunto del sistema, ya que permitiría al electorado ver quiénes realmente no cumplen con las exigencias básicas del mismo.

Es cierto que el supuesto resuelto por la Sentencia 79/2014 y el de la 226/2016 difieren en cuanto a la condición de quien realiza la crítica. En el primero es un profesional de la información, sujeto activo privilegiado de las libertades comunicativas que además no está ligado en absoluto al partido, y en el segundo una afiliada a la que, como tal, se le exige un cierto grado de lealtad. Esto puede modular los términos de la ponderación, incorporando la autonomía de la voluntad del individuo a la misma, pero en absoluto explica por qué el mismo bien jurídico, la imagen institucional del partido, se

34 STC 79/2014, de 28 de mayo, FJ 30.

35 SSTEDH, Lindon, Otchakovsky-Laurens y July c. Francia [G.S.], no 21279/02 y 36448/02, 22 de octubre 2007, par. 46; y Magyar JetiZrt c. Hungría, no 11257/16, 4 de diciembre de 2018, par. 81.

36 STEDH, Chitic c. Rumanía, no 6512/13, 14 de enero de 2020, par. 51. 
fundamenta en un caso en el derecho al honor, en línea con la doctrina del Tribunal Europeo de Derechos Humanos, y en el otro en el derecho de asociación. Y esto es importante porque es el artificio en el que se basa el Tribunal Constitucional para no aplicar los criterios de valoración establecidos para el supuesto de la libertad de expresión política. En lugar de ponderar si la restricción es necesaria en una sociedad democrática, lo hace únicamente a partir del interés privado del partido en ser percibido positivamente para obtener de ello un rédito electoral, lo que constituye una aplicación selectiva y a conveniencia de la doctrina de Estrasburgo que no se ajusta al significado del art. 10.2 CE. Y tampoco obliga a quienes reciben la crítica a demostrar el carácter injurioso o innecesario de esta, rompiendo la regla de la inversión en la carga de la prueba que él mismo había establecido respecto de las personas públicas cuando son objeto de crítica ${ }^{37}$.

Parece claro que, expulsando el derecho al honor de la ecuación, se buscaba soslayar la particular debilidad de la protección que dispensa ante la crítica política como resultado de la doctrina de la posición preferente. Paralelamente, se potencia el derecho a la autoorganización del partido como ente colectivo frente a la posición de los afiliados, reforzando el valor de la normativa interna como instrumento para limitar sus derechos fundamentales por el hecho de estar sometidos a un deber genérico de lealtad que recuerda en su contenido al que se deduce de las relaciones privadas de naturaleza laboral a partir de la buena fe contractual, aunque lo supera en intensidad ${ }^{38}$.

Sin embargo, presentar tal cosa como una consecuencia del reconocimiento de los partidos como titulares del derecho de asociación resulta excesivo, ya que de este no se desprende que los intereses de un ente colectivo, siquiera privado, deban prevalecer incondicionalmente sobre los de sus miembros (Pérez-Moneo, 2012: 83-84). Pero también, y quizá más importante, se olvida que la unidad y la cohesión interna deben ponerse en relación con el pluralismo y, en el caso de los partidos, supeditarse necesariamente al principio democrático (Salvador Martínez, 2019: 412), lo cual parece difícilmente compatible con una doctrina que diluye la individualidad de la persona en su condición de afiliado

37 STC 49/2001, de 26 de febrero, FJ 7o.

38 Si bien la buena fe en las relaciones laborales limita para el trabajador la posibilidad de expresarse sobre «aspectos generales o singulares del funcionamiento y actuación de la Empresa en la que presta servicios» (STC 88/1985, de 19 de julio, FJ 2º), un resultado bastante similar a lo que se plantea en la relación de afiliación política, de ella no se deriva un «deber genérico de lealtad con un significado omnicomprensivo de sujeción del trabajador al interés empresarial» que permita limitar sus derechos fundamentales para protegerlo (STC 56/2008, de 14 de abril, FJ 6º y las allí citadas), como sí parece existir en el caso de los partidos políticos, donde la sumisión del sujeto a la voluntad de la organización resulta ser más intensa. 
para restringir su capacidad de intervenir libremente en el debate público. Porque más allá de limitaciones que pudieran ser razonables, como promocionar o pedir el voto para otra opción política, se impide al afiliado plantear cualquier discrepancia o diferencia sobre aspecto alguno que tenga que ver con la formación a la que pertenece ${ }^{39}$, limitando sus opciones individuales a replicar el discurso del partido o al silencio. Y esto último incluso sería discutible si se llega a entender el deber de "colaboración positiva» como una obligación proactiva de defensa pública del programa del partido.

Esto constituye una restricción considerable de los derechos políticos de la persona consecuencia, paradójicamente, de su decisión de integrarse en un ente colectivo con el objetivo de poder ejercerlos de manera más completa. Pero, además, la solución del Tribunal Constitucional provoca un efecto negativo sobre el proceso de formación de la opinión pública. Parece aceptarse, y casi protegerse, la opacidad de los procesos internos de los partidos, subestimando la importancia que pueda tener su conocimiento para el conjunto de la sociedad e ignorando el valor que el debate público puede aportar a la conformación de la voluntad de la organización.

Con todo ello se llega a una situación absurda: entender que un partido político, una asociación privada privilegiada pero asociación privada a fin de cuentas según la propia jurisprudencia constitucional, resulta más protegido que las instituciones del Estado o quienes las ocupan frente a críticas a su funcionamiento o ataques a su imagen ${ }^{40}$, aunque sea únicamente en relación a sus miembros.

39 El Tribunal Constitucional acaba identificando el deber de lealtad del afiliado con una «obligación de contención en las manifestaciones públicas» sobre la línea política, el funcionamiento interno del partido o «aspectos de la política general en lo que puedan implicar a intereses del propio partido» (STC 226/2016, cit., FJ 7o), lo que en la práctica supone cualquier cuestión que guarde relación con este.

40 La jurisprudencia constitucional ha entendido que la libertad de expresión ampara «los juicios de valor de ámbito político o los que se refieren directamente al funcionamiento de las instituciones públicas», que están obligadas a soportarla «en el contexto de una sociedad democrática» (SSTC 23/2010, de 27 de abril, FJ 3o y 6/2020, de 27 de enero, $\mathrm{FJ} 3^{\mathrm{o}}$ y $4^{\circ}$ ). Y aunque inicialmente consideró que el límite a la crítica hacia los representantes de una institución o titulares de un cargo público se encontraba en aquellas manifestaciones cuya intención fuera exclusivamente ultrajante o vejatoria (STC 177/2015, de 22 de julio, FJ 3º.c), el Tribunal Europeo de Derechos Humanos ha entendido que incluso manifestaciones particularmente provocadoras o radicales en sus formas contra una institución (la Jefatura del Estado en el caso) resultan admisibles mientras se puedan entender como expresiones de insatisfacción y protesta dirigidas hacia aquella o el orden político en sí mismos, y no como ataques personales 
Frente al carácter incondicional que se ha otorgado a la defensa de la imagen del partido, sería más razonable entender que el afiliado debería gozar de capacidad de disentimiento público frente al mismo por más que su condición suponga algún factor diferencial en relación al ciudadano corriente. Sobre todo si internamente esta posibilidad está en la práctica restringida o impedida, cosa que también habría que tener en cuenta. Por otro lado, el funcionamiento de un partido no es en absoluto irrelevante para el devenir del sistema político, por lo que también habrá que considerar el interés público constituido por la necesidad de que los electores puedan comprobar de modo efectivo si quienes aspiran a detentar el poder, los cuadros de la organización, están verdaderamente comprometidos con el principio democrático.

Así, como regla general debería entenderse protegida (y por tanto inmune a la potestad sancionadora del partido) toda discrepancia formulada de manera razonable y razonada sobre cuestiones concretas referentes al funcionamiento o la posición del partido, no así sobre el conjunto del programa o la política general, en momentos en los que el perjuicio electoral a la organización sea mínimo (Oliver y Calafell, 2007: 19). En caso de manifestaciones que verdaderamente resulten excesivas o se realicen en momentos clave, la doctrina de la posición preferente obliga a vigilar la estricta proporcionalidad de las sanciones en función de la gravedad del perjuicio para el partido como tal, no para sus dirigentes en términos individuales, por mucho que en ocasiones sea complicado separar ambos planos (Flores Giménez, 1998: 214).

Sin embargo, aquellas críticas públicas que evidencien una disfunción grave en el funcionamiento del partido o una vulneración del principio democrático o de los derechos de los afiliados deberían resultar amparadas en todo caso con independencia del momento en el que se produzcan o su contenido, ya que aquí la libertad de expresión individual del afiliado actuaría como verdadero contrapoder frente a abusos que se benefician de la permisividad del actual marco normativo. Con ello se colocaría a la opinión pública como vigilante directa de los procesos internos partidistas, dando cumplimiento a su función como mecanismo de garantía del correcto funcionamiento del Estado constitucional, erigido en el interés superior en esta cuestión. Y esto aun a costa de frustrar las aspiraciones electorales o comprometer la supervivencia misma de aquellos partidos cuyos líderes no actuaran de manera diligente, porque no existe ninguna razón para proteger frente a sus propios actos a organizaciones que vulneran las previsiones constitucionales, especialmente si se tiene en cuenta que la sustitución de unos partidos por otros encaja en la evolución natural de un sistema político. Lo que quizá sí se necesitaría entonces para evitar el debilitamiento institucional serían medidas

(STEDH, Stern Taulats y Roura Capellera c. España, no 51168/15 y 51186/15, 13 de marzo de 2018, pars. 38 y 39). 
que aseguren el compromiso de las nuevas fuerzas políticas con las máximas constitucionales para evitar caer en los mismos vicios demasiado pronto.

\section{VALORACIONES FINALES}

Teniendo en cuenta el carácter progresivo de la conformación de la opinión pública y la exigencia democrática que recae sobre los partidos, primer espacio donde se empiezan a conformar los términos del debate político y se configura la agenda de actuación de las instituciones estatales, no parece que se puedan imponer sobre sus afiliados restricciones al ejercicio de su libertad de expresión diferentes de las que rigen para el común de los ciudadanos cuando realizan manifestaciones que se puedan considerar de interés para el debate político en los espacios internos de la organización. Sin embargo, en cuanto al ejercicio de este derecho en el ámbito público, el Tribunal Constitucional ha resuelto que la vinculación a un partido impone al sujeto obligaciones añadidas que le impiden cuestionar sus actuaciones o decisiones, pudiendo ser legítimamente sancionado por la organización al hacerlo.

La afiliación política es concebida así como un factor modificativo del estatus de ciudadanía del individuo que, como consecuencia de su condición, asumida teóricamente para poder ejercer mejor sus derechos de participación, ve restringido uno tan relevante como la libertad de expresión. Y cabría valorar qué efecto modulador podría tener sobre el resto de derechos, porque se abre una vía peligrosa en este sentido.Todo como consecuencia de deducir de la autonomía de la voluntad cuando se materializa en la integración en una asociación política un deber particularmente intenso de lealtad hacia los intereses corporativos de esta. Pero en lugar de identificar estos intereses con los fundamentos ideológicos del partido o el resultado de procesos internos desarrollados con las debidas garantías, el Tribunal Constitucional los asimila sin más a las decisiones de los órganos directivos, sin que parezca importar si se alinean más o menos con las voluntades o el consenso de sus miembros, encubren intereses particulares de los cuadros de la organización o vulneran los derechos de las minorías discrepantes.

El carácter democrático de tales actuaciones aparece en la argumentación del Tribunal como una presunción absoluta, una postura poco realista que solo sirve para reforzar la posición de unas élites partidistas que se ven con vía libre para emplear la disciplina interna a voluntad frente a cualquier disidencia, lo que implica en última instancia negar que esta sea posible.De manera acorde con fallos anteriores y la propia legislación, la exigencia democrática se reduce a unas reglas formales que matizan la libertad asociativa, pero no la condicionan del modo determinante que sería deseable teniendo en cuenta cuánto suponen los partidos en la democracia constitucional. Y lo que puede implicar para el funcionamiento y la supervivencia misma de esta la renuncia a asegurar 
dentro de estas organizaciones un espacio amplio para los derechos de participación.

Al contrario, la protección de la consideración social de los partidos políticos, construida de modo completamente independiente al respeto demostrable por el principio democrático, se erige como interés dominante. Probablemente por temor a que la revelación de ciertas interioridades acabe por desembocar en un cuestionamiento del sistema constitucional mismo. Sin embargo, esta intención de proteger el statu quo parece presentar más peligros que ventajas, y no solo desde la consideración individual de la libertad de expresión del afiliado, cuyo alcance se ve reducido de tal manera que hace difícil la supervivencia dentro de la organización para aquellos que no estén dispuestos a seguir ciegamente al aparato. En un momento en el que las formas y la legitimidad del modelo democrático liberal parecen generar más recelos que confianza, reforzar la opacidad de los partidos y privar a la sociedad de conocimiento y, por tanto, de capacidad de control sobre la realidad de su funcionamiento no parece la mejor opción. Esto no solo repercute negativamente en la opinión pública, y con ello en la calidad democrática del sistema, sino también en los propios partidos. Dificulta que el debate público pueda influir en sus decisiones y sus modos de actuación, reforzando en última instancia su aislamiento. También debilita su estructura interna, ya que ante la falta de garantías frente a los abusos de las élites será más probable que los afiliados opten por abandonar la organización cuando cambien los equilibrios de poder o se sientan incómodos, lo que facilita la conversión de los partidos de masas en simples estructuras electorales de apoyo a unos cuadros que devienen inamovibles. Y con ello, la involución de la democracia hacia un mero mecanismo plebiscitario de apoyo o rechazo a propuestas cerradas definidas desde el poder donde no hay lugar para la argumentación y la búsqueda del interés común mediante el debate.

\section{Bibliografía}

Aragón Reyes, M. (2016). Planteamiento general: partidos políticos y democracia directa. En P. Biglino Campos (coord.). Partidos politicos y mediaciones de la democracia directa (pp. 19-35). Madrid: Centro de Estudios Políticos y Constitucionales.

Burguera Ameave, L. (2015). El derecho a la reputación o buen nombre de los partidos políticos. Notas a la STC 79/2014, de 28 de mayo. Teoría y Realidad Constitucional, 35, 663-675. Disponible en: https://doi.org/10.5944/ trc.35.2015.14934.

Fernández Segado, F. (2004). Algunas reflexiones sobre la Ley Orgánica 6/2002, de Partidos Políticos, al hilo de su interpretación por el Tribunal Constitucional. Revista de Estudios Politicos, 125, 109-155. 
Flores Giménez, F. (1998). La democracia interna de los partidos políticos. Madrid: Congreso de los Diputados.

Gallardo Moya, R. (1996). Derecho de asociación y exigencia de democracia interna de los partidos políticos (Comentario a la STC 56/1995, de 6 de marzo). Derecho Privado y Constitución, 8, 237-250.

García Canales, M. (2002). El derecho al honor de quienes ejercen actividad con relevancia política. En La democracia constitucional. Estudios en homenaje al Profesor Francisco Rubio Llorente (pp. 487-508). Madrid: Congreso de los Diputados.

García Pelayo M. (1977). Las transformaciones del Estado contemporáneo. Madrid: Alianza.

- (1986). El Estado de Partidos. Madrid: Alianza.

Garrido López, C. (2017). El dilema de la democracia en el interior de los partidos. Teoria y Realidad Constitucional, 40, 317-347. Disponible en: https://doi. org/10.5944/trc.40.2017.20915.

Gómez Montoro, A. J. (2002). La titularidad de derechos fundamentales por personas jurídicas: un intento de fundamentación. Revista Española de Derecho Constitucional, 65, 49-105.

Gómez Yánez, J. A. (2016). La democracia en los partidos y su necesaria regulación legal. En C. Garrido López y E. Sáez Royo (coords.). La reforma del Estado de partidos (pp. 39-67). Madrid: Marcial Pons.

Habermas, J. (2005). Tres modelos de democracia. Sobre el concepto de una política deliberativa. Polis, 10, 1-9.

Hernández Valle, R. (2002). La democracia interna de los partidos políticos. Revista de Derecho Politico, 53, 473-492. Disponible en: https://doi.org/10.5944/ rdp.53.2002.9249.

Kelsen, H. (1934). Esencia y valor de la democracia. Barcelona: Labor.

Loewenstein, K. (1976). Teoría de la Constitución. Barcelona: Ariel.

Michels, R. (1969). Los partidos politicos. Buenos Aires: Amorrortu.

Miguel Bárcena, J. de (2015). Libertades comunicativas y derechos de la personalidad: límites y colisiones. En J. C. Gavara de Cara, J. de Miguel Bárcena, y D. Capodiferro Cubero (eds.). El control judicial de los medios de comunicación (pp. 65-100). Barcelona: J. M. Bosch. Disponible en: https://doi.org/10.2307/j. ctvrzgzjh.5.

Moretón Toquero, A. (2015). Novedades en torno a las libertades de expresión e información en la jurisprudencia del Tribunal Constitucional y del Tribunal Europeo de Derechos Humanos. En J. C. Gavara de Cara, J. de Miguel Bárcena y D. Capodiferro Cubero (eds.). El control judicial de los medios de comunicación (pp. 25-64). Barcelona: J. M. Bosch. Disponible en: https://doi.org/10.2307/j. ctvrzgzjh.5.

Navarro Méndez, J. I. (2000). ¿¿Pueden los partidos políticos expulsar «libremente» a sus afiliados? Revista de Estudios Politicos, 107, 269-295.

Navas Castillo, F. (2009). Libertad de expresión y derecho a la información. En A. Torres del Moral (dir.). Libertades Informativas (pp. 89-109). Madrid: Colex. 
Oliver Araujo, J. y Calafell Ferrá, V. J. (2007). Los estatutos de los partidos políticos: notas sobre su singularidad jurídico-constitucional. Revista de Estudios Políticos, 137, 11-36.

Pérez-Moneo, M. (2012). La selección de candidatos electorales en los partidos. Madrid: Centro de Estudios Políticos y Constitucionales.

Salvador Martínez, M. (2019). La libertad de expresión de los afiliados a un partido político y sus límites (a propósito de la STC 226/2016). Revista Española de Derecho Constitucional, 115, 391-422. Disponible en: https://doi.org/10.18042/ cepc/redc.115.13.

Serrano Maíllo, I. (2011). El derecho a la libertad de expresión en la jurisprudencia del Tribunal Europeo de Derechos Humanos: dos casos españoles. Teoría y Realidad Constitucional, 28, 579-596. Disponible en: https://doi.org/10.5944/ trc.28.2011.6973.

Solozábal Echavarría, J. J. (1991). La libertad de expresión desde la teoría de los derechos fundamentales. Revista Española de Derecho Constitucional, 32, 73-113.

- (2001). Los derechos colectivos desde la perspectiva constitucional. Cuadernos de Derecho Público, 12, 79-115.

Tajadura Tejada, J. (2015). La democracia interna en los partidos políticos: marco constitucional, desarrollo legislativo y realidad política. En M. Contreras Casado y C. Garrido López (eds.). Interiores del Príncipe Moderno (pp. 57-110). Zaragoza: Comuniter.

Torres del Moral, A. (1982). Crisis del mandato representativo en el Estado de partidos. Revista de Derecho Político, 14, 7-30. Disponible en: https://doi. org/10.5944/rdp.14.1982.8163.

- (2002). Ampliaciones y minoraciones de la libertad de comunicación pública. En La democracia constitucional. Estudios en homenaje al Profesor Francisco Rubio Llorente (pp. 539-571). Madrid: Congreso de los Diputados.

Vidal, C. (2014). La libertad de expresión en la jurisprudencia del Tribunal Constitucional federal alemán. En P. J. Tenorio Sánchez (dir.). La libertad de expresión. Su posición preferente en un entorno multicultural (pp. 245-266). Madrid: Wolters-Kluwer.

Vírgala Foruria, E. (2015). La regulación jurídica de la democracia interna en los partidos políticos y sus problemas en España. Teoría y Realidad Constitucional, 35, 225-280. Disponible en: https://doi.org/10.5944/trc.35.2015.14919. 